\title{
Trials of a Beginning ABET Evaluator: An Unauthorized Tell-All Biography
}

\author{
Allen C. Estes \\ United States Military Academy
}

\section{Introduction}

The Accreditation Board for Engineering and Technology (ABET) has now evaluated a large number of schools under the Engineering Criteria (EC) $2000^{1}$ where the focus is on the establishment of outcomes and objectives, the two-loop assessment process, and the resulting system of continuous improvement. This paper highlights the experience of a relatively new ABET evaluator. The author has made the transition in two years from someone with no knowledge of the accreditation process to an educator who has:

- attended evaluator training

- served as an observer

- prepared a self-study for his own Civil Engineering program

- prepared for and survived an ABET evaluation of his own program, and

- served as an ABET evaluator for a sister Civil Engineering program.

Whenever the rules for something as important as accreditation change dramatically as they have with the implementation of the EC2000, considerable angst from the participants is inevitable. The system is still evolving and the sharing of information is the best way to eliminate misperceptions and share the secrets to success. This paper provides a summary of this experience, lessons learned along the way, advice to those who are preparing for their own accreditation visits, and the perspective of the accreditation process from someone who is new to the system, yet has very recent experience on both sides of the accreditation process.

\section{Evaluator Training}

Prior to certification as an ABET evaluator, there are two steps that must occur - at least within the civil engineering discipline:

- A candidate must attend evaluator training. It is usually conducted in conjunction with a well-attended professional conference as a matter of ease and efficiency.

- A candidate serves as an observer during an ABET visit and learns from a certified evaluator.

ABET attempts to find an equal number of evaluators from academia and from professional practice.

The evaluator training lasts between a half-day and a day and is laden with terminology. It seems overwhelming at first. There are abbreviations associated with the possible ratings (e.g., IV, IR, NGR) and a flow chart of options depending on whether an initial visit or a follow-up visit is being conducted. The requirements for continual assessment, the 
creation of objectives and outcomes, the minimum baseline criteria, and the philosophy behind EC2000 are covered. The standards of enforcement are illustrated through a series of situational exercises. It does not all sink in during the training. Repetitive reference to the handouts will help reinforce the material - especially in preparation for the observer visit.

\section{Observer Visit}

The observer visit is most beneficial when the observer participates to the fullest extent possible, to include all of the pre-visit preparation and completing all of the required paperwork as if the observer is conducting the evaluation. An ABET visit passes very quickly. It typically commences on a Sunday afternoon and ends by noon on Tuesday with a final out brief to the administration early Tuesday afternoon.

There are many forms and checklists that need to be completed by noon on Tuesday. A typical evaluator will spend the precious site visit time reviewing documentation, observing classes and activities, visiting lab facilities, interviewing faculty members and students, meeting the Advisory Board, evaluating an assigned support activity, and attending meetings with the rest of the team. There is not enough time to do all of this thoroughly. To be successful, the draft of the final report needs to be completed prior to the start of the visit. This underscores the importance of the self-study and pre-visit communication with the program being evaluated. The observer needs to be included in all of this or else $70 \%$ of the training value is lost.

The observer typically will attend everything the evaluator attends. If the observer is well prepared, he or she acts as a valuable set of eyes and can be an asset to the evaluation. In some cases, the evaluator and observer can split some of the interviews and compare notes afterward.

The observed must remember that he is only the observer and should refrain from undermining the program evaluator in any way. The observer should participate fully in the process, but should not disagree publicly with the evaluator. Such issues are best resolved in private conversation with the evaluator having the final say. The observer, as the name implies, should be seen and not heard in the public forum.

A good evaluator will solicit the observer's opinion and will require the observer to complete all of the paperwork independently. The observer will quite often include something the evaluator would have forgotten or provide a unique perspective. As a result, the observer will depart with a copy of his initial effort and a complete final report to be used as a guide during his first evaluation visit. The Major University samples provided by $\mathrm{ABET}^{2}$ are also helpful guides.

Everybody gets rated in this process. Obviously, the evaluator is judging an individual program. The evaluator rates the observer and the rating carries significant weight toward whether the observer is invited back as an evaluator. All team members evaluate the team 
chief and the Department Head of the program being visited rates the evaluator

\section{Evaluator Preparation}

Having been a full participant as an observer under the tutelage of an experienced evaluator prepared me greatly for my first tour as an evaluator. Careful examination of the self-study and the transcripts are both critical and should provide the agenda for the visit. I found that a rigorous review of the transcripts was a good first step and well worth the time expended. Each program under evaluation will provide five student transcripts to the evaluator - the usual guidance is to provide the first five consecutive transcripts from the most recently graduated class starting with a specific letter of the alphabet. For someone unfamiliar with a program, the transcripts provide great insight to what courses comprise the program, what electives are available, the grading standards, the acceptability of transfer credits, the degree of academic counseling required, and whether or not a mechanism exists to ensure all students meet the requirements. The familiarity gained from the transcripts and the concomitant cross-referencing with the course catalogue makes the content of the self-study more understandable.

An evaluator has a checklist of items that matches the prescribed format of the self-study. An evaluator reads the self-study looking to determine how well a program meets the ABET requirements. A wise program director will ensure the submitted self-study is in the proper format and answers the necessary questions. It will make the program easier to evaluate, will generate fewer issues at the site visit and will convey a more favorable impression of the program. A program director will naturally portray his or her program in a favorable light, but the director should be cautious about overstating accomplishments or including items that cannot be substantiated. In many cases, such comments generate questions from evaluators that otherwise would never have been asked.

The ABET evaluation should be an open process with the goal of having no surprises at the site visit. After studying the relevant documents, the evaluator should communicate with the program director to list areas where more information is needed and where the program might not meet the accreditation criteria. In many cases, the inspected program can provide additional information and documentation that resolves the issue. Sometimes the response might reinforce the view that a problem exists. With careful prior study, the evaluator can target those areas that need to be observed and can determine who are the best people to interview on relevant subjects. Providing this information in advance allows the program director to prepare an efficient itinerary, arrange a tour, and schedule meetings with the right individuals.

\section{The Evaluation Visit}

Since the visit begins on a Sunday afternoon when most people are not around, that is a great time to tour facilities, review documentation, obtain an orientation briefing, and have a detailed discussion with the program director. Monday is a good day to conduct interviews of faculty and students and observe activities. The school will often host a 
luncheon on Monday and invite members of the advisory board. Every program is supported by other parts of the university. Typically a team chief will assign each evaluator a support activity such as the math/chemistry/physics departments, the social sciences/humanities departments, the library, the computer support center, or the student union to visit and evaluate. Tuesday morning is ideally reserved for meetings that address issues that arise during the visit, preparation of the final paperwork, and a final briefing to the program director. An evaluator should meet with the program director daily to honestly report issues. The evaluator should report the final results to the program director prior to the final briefing to the upper level administration in the afternoon. Again, nobody wants to be surprised and nobody wants to feel that an issue could have been resolved if he had only been informed.

My initial reason for becoming an ABET evaluator was to prepare for my own program's ABET visit. I was not familiar with EC2000 and an effective way to understand a process is to inspect somebody else. My initial concern about the process was that it appeared terribly unfair - a program was potentially at the mercy of the background, hidden agenda, and temperament of the assigned evaluator. This process revealed that there are at least two levels of potential fairness built into the system.

The first is the team chief who is himself an experienced evaluator and helps bring consistency and fairness to the process. As a university prepares for an ABET visit, the programs tend to trade ideas, communicate, and adopt some of the same means of assessment. The different program evaluators meet together with the team chief as least four times during the inspection visit and discuss potential findings as a group. The team chief moderates discussion to obtain consistency - especially when several programs adopt the same standard and two evaluators want to rate them differently. The evaluation team members tend to bring an aberrant evaluator back in line.

The second line of defense is that the evaluator's ruling is not final. Institutions have the right to respond to factual errors, to make a case that an evaluator made an unfair call, and to demonstrate that a problem has been promptly fixed. The accreditation rating does not become final until the Engineering Accreditation Commission meets as a body. As the committee meets, many schools receive a more favorable rating as a result of this process. The system is much fairer than it initially appeared.

Most of the ABET criteria are common to all programs, but criterion 8 is left for the individual disciplines to add requirements specific to that discipline. In the case of civil engineering, the American Society of Civil Engineers program criteria are often more difficult to meet than the ABET general criteria. The requirements to have all instructors teaching design courses be professionally licensed, for programs to demonstrate proficiency in four sub-disciplines, to require coverage of probability and statistics, and to ensure that a program is not dependent on a single individual can be challenging to implement. ASCE also provides an unofficial Commentary to help evaluators and program directors interpret the program criteria and its associated terminology. 
My final observation is that the difference between an observation, concern, weakness, or a deficiency is often a judgment call. The ABET documentation attempts to quantify the standard, but human beings are making decisions based on human observations and intangibles are inevitable. The biggest intangible is attitude. It is harder to give an adverse rating to a program that is dedicated, enthusiastic, and anxious to rapidly fix any shortcomings. A faculty that appears indifferent, obstinate and resistant to advice is more likely to receive an unfavorable rating.

\title{
Conclusion
}

In the past two years, I have learned a lot about the ABET evaluation process and have a greater understanding as to the value behind it and the fairness of the system. It is by no means perfect, but it provides a valuable self-enforcement mechanism to ensure our engineering programs are of high quality and that the ABET-accredited label has meaning. $\mathrm{ABET}$ is not some amorphous agency looking down from above. ABET is us representatives from the academic and professional practice communities who are evaluating and being evaluated. We are policing ourselves and if we do it right, nobody else will ever have to.

It will be interesting to see the successive evaluations under the EC2000 guidelines. Many schools have developed outcomes and objectives and implemented an assessment process for continuous improvement. The unanswered question will now be whether these systems are sustainable. Many schools have established good systems supported with one or two years of data and their assessment process in its infancy. The real test will come with the next evaluation where schools must show six years of data and program growth through slow and fast loop assessments. Stay tuned.

\section{Bibliography}

1. Accreditation Board for Engineering and Technology. Criteria for Accrediting Engineering Programs. Engineering Accreditation Commission, Baltimore, MD., 2001.

2. Accreditation Board for Engineering and Technology. Engineering Criteria 2000 Program Evaluator Training, Engineering Accreditation Commission, Baltimore, MD., April 2000

3. American Society of Civil Engineers. Commentary, Civil Engineering Program Criteria, Committee on Curricula and Accreditation, Reston, VA, 2002.

\begin{abstract}
ALLEN C. ESTES
Colonel Allen C. Estes is an Associate Professor and Civil Engineering Division Director at the United States Military Academy (USMA). He is a registered Professional Engineer in Virginia. COL Estes received a B.S. degree from USMA in 1978, M.S. degrees in Structural Engineering and in Construction Management from Stanford University in 1987 and a Ph.D. degree in Civil Engineering from the University of Colorado at Boulder in 1997.
\end{abstract}

"Proceedings of the 2003 American Society for Engineering Education Annual Conference \& Exposition Copyright @ 2003, American Society for Engineering Education” 